\title{
ANÁLISE DA OCORRÊNCIA DE FOCOS DE CALOR E RELAÇÕES COM A OCORRÊNCIA DE INCÊNDIOS NO MUNÍCIPIO DE SALINAS, MINAS GERAIS
}

Eduarda Soares Menezes - eduarda_menezs@hotmail.com

Universidade Federal dos Vales do Jequitinhonha e Mucuri

Marcos Vinícius Miranda Aguilar - aguilarmarcos2009@ hotmail.com

Instituto Federal do Norte de Minas Gerais

Aline Ramalho dos Santos - alineramalho13@ @otmail.com

Universidade Federal do Espirito Santo

Tarlei Aparecido Santos - tarleyengflorestal@gmail.com

Instituto Federal do Norte de Minas Gerais

Lara Soares Menezes - laras.menezes@ gmail.com

Universidade Federal de Minas Gerais

Ricardo Ramalho dos Santos - ricardokiau@ hotmail.com

Universidade Federal dos Vales do Jequitinhonha e Mucuri 


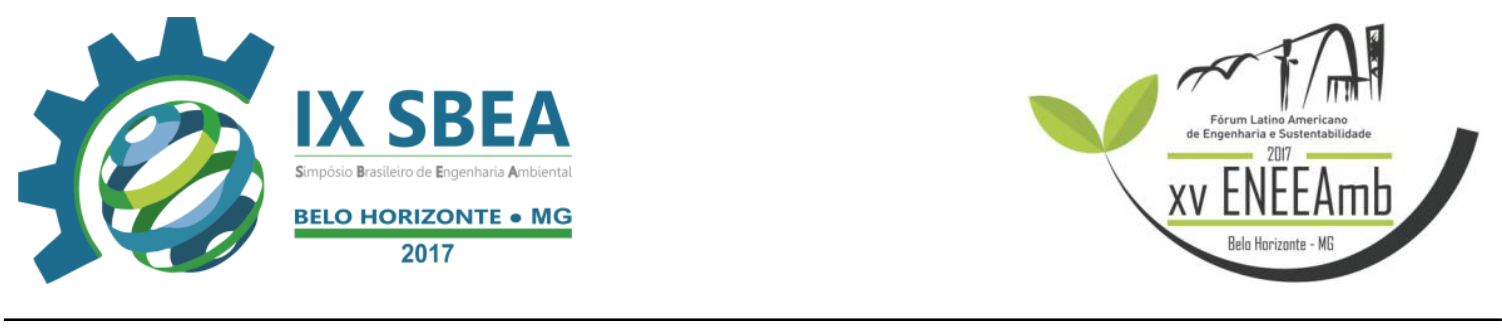

\section{RESUMO}

O presente trabalho teve como objetivo analisar os registros de focos de calor no munícipio de Salinas e relacioná-los com a ocorrência de incêndios por meio das ferramentas do sistema de informações geográficas. O estudo compreendeu o período 2012 e 2016, onde o levantamento das informações sobre os focos de calor foram realizados através do Instituto Nacional de Pesquisas Espaciais (INPE). O processamento de dados ocorreu através do software QGIS, a partir dos mapas em formato vetorial. No ano de 2013 verificou-se uma mudança drástica na distribuição espacial dos focos mais significativos, região caracterizada por solo exposto e cobertura vegetal desmatada. Em 2015 e 2016, mudanças na quantidade e nos focos de calor foram positivas, uma vez que modificaram sua dimensão, podendo-se afirmar que houve menores registros. Com base nas análises dos resultados obtidos no município de Salinas - MG, as maiores ocorrências de focos de calor encontram-se próximas as rodovias, ou áreas do município que apresentam a pecuária como a principal atividade econômica.

Palavras-chave: Degradação, Geoprocessamento, Monitoramento ambiental.

\section{INTRODUÇÃO/OBJETIVO}

Na região norte de Minas desponta-se uma base econômica voltada à pecuária extensiva e a agricultura de subsistência. Caracteriza-se pela zona de transição entre dois grandes biomas, a caatinga e o cerrado, predominando o segundo e suas variações.

A queima da pastagem como alternativa de manejo para a criação de bovinos é uma das principais práticas associadas ao fogo nessa área, realizando o uso de extensas vegetações de pastagem nos locais com cerrado mais abertas, como por exemplo, o campo limpo e campo sujo (MIRANDA et al., 2013). Essa modificação na paisagem tem causado aumento na frequência de incêndios florestais, alterando a capacidade de recuperação dos elementos da biota (FIEDLER et al., 2006).

A ocorrência de queimadas provoca diversos impactos ambientais como: o empobrecimento do solo além de reduzir a penetração de água no subsolo, a perda da biodiversidade de flora e fauna, liberação de gases estufa, além de causar inúmeros 


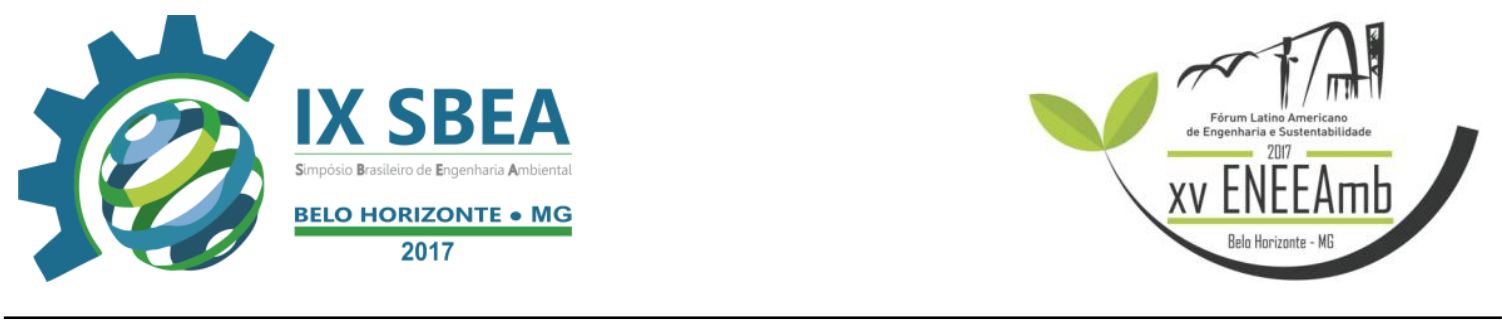

prejuízos significativos à sociedade como um todo, entre outros danos acometidos a este tipo de ocorrência (CORRÊA, et al., 2013)

Nesse sentido, para estabelecer políticas de controle e prevenção, faz-se necessário conhecer o perfil dos incêndios. As estatísticas de ocorrência dos incêndios em vegetação são as principais ferramentas para se traçar esse perfil (CIPRIANI et al., 2011). Pesquisas sobre incidência de focos de queimadas por meio do uso do geoprocessamento resultam em diversas aplicações, que garantem a identificação dos focos de calor a partir de do uso de algoritmos aplicados em processamento de imagens geradas de satélites, assim esses dados são indispensáveis para analisar a ocorrência, e distribuição desses focos de calor.

O monitoramento de queimadas em imagens de satélites é imprescindível para regiões sem meios intensivos de acompanhamento, condição esta que representa a situação geral do país (INPE, 2012). Nesse contexto, o Sistema de Informações Geográficas (SIG), juntamente com as técnicas de geoprocessamento conformam-se como ferramentas bastante significativas para o monitoramento por meio de mapas manipulados nesse sistema integrados aos focos contidos na região de interesse.

Portanto, as informações sobre a acurácia dos algoritmos necessitam ser atualizadas constantemente, visto que no decorrer do tempo, o desempenho adquirido pelos sensores e as condições radiométricas sofrem alterações (MIRANDA et al., 2013).

Nesse sentido, o presente trabalho teve como objetivo analisar os registros de focos de calor e relacioná-los com a ocorrência de incêndios no munícipio de Salinas, Minas Gerais por meio do uso de ferramentas do sistema de informações geográficas.

\section{METODOLOGIA}

O estudo foi realizado no município de Salinas - MG, localizado entre os paralelos de $15^{\circ}$ e $16^{\circ}$ de latitude Sul e meridianos de $41^{\circ}$ e $43^{\circ}$ a Oeste de Greenwich e situado na mesorregião do Norte de Minas (Figura 1), que compreende cerca 1.862,117 $\mathrm{Km}^{2}$, e uma população estimada de 41.494 habitantes (IBGE, 2016). 

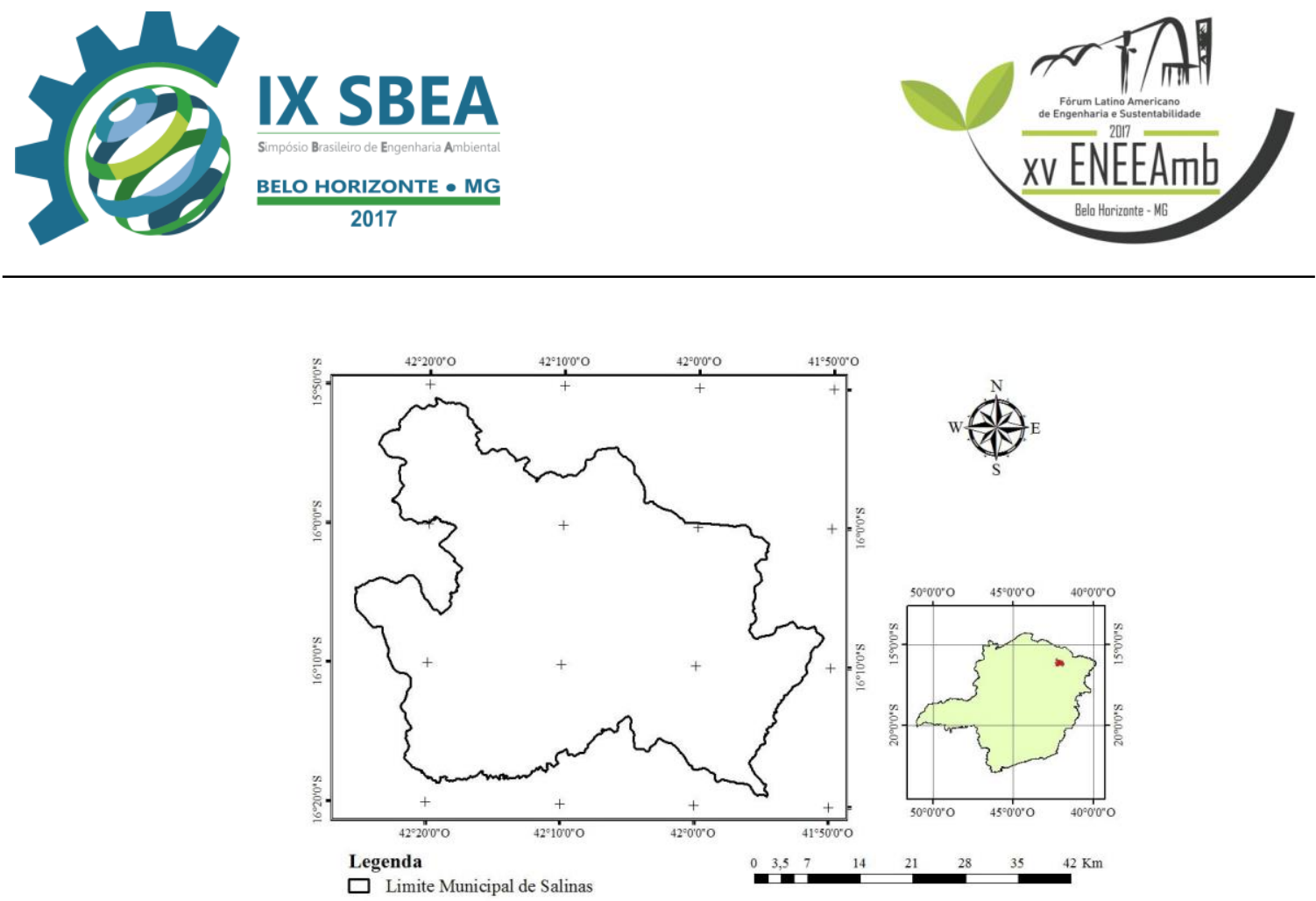

Figura 1 - Localização da área de estudo no estado de Minas Gerais.

O município de Salinas se caracteriza por apresentar clima semiárido, com temperaturas elevadas e uma estação das chuvas compreendida entre outubro e março. Entre os meses que compreendem Julho a Novembro, foram registrados um aumento significativo na ocorrência de incêndios na região (Figura 2), fortemente relacionado as condições climáticas, presença de material combustível e realização de queimadas pela população.

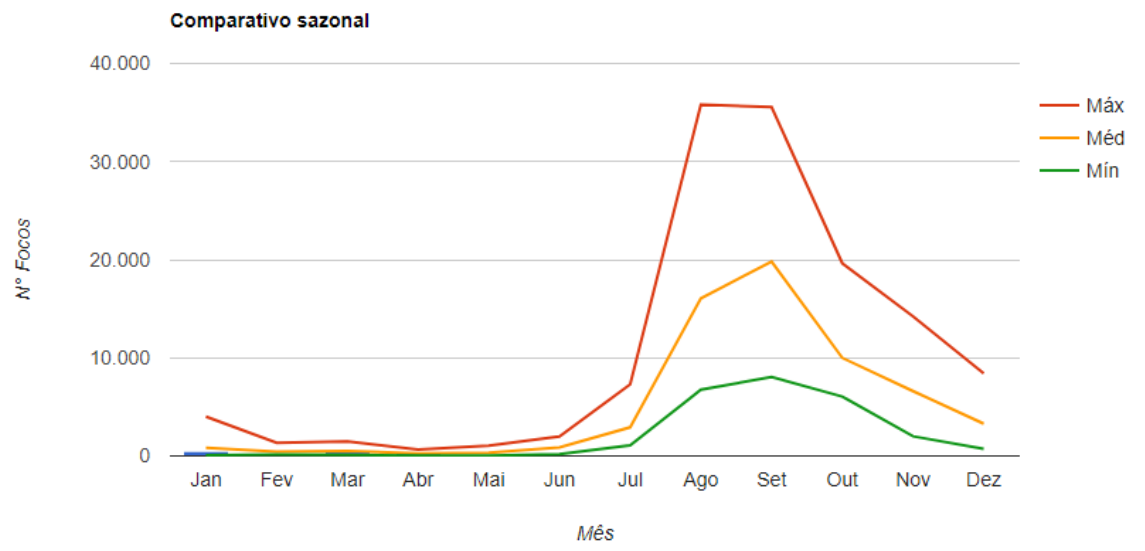

Figura 2 - Comparativo sazonal da ocorrência de incêndios por meio de classificações de intensidade para o município de Salinas, Minas Gerais.

Fonte: INPE, 2016. 


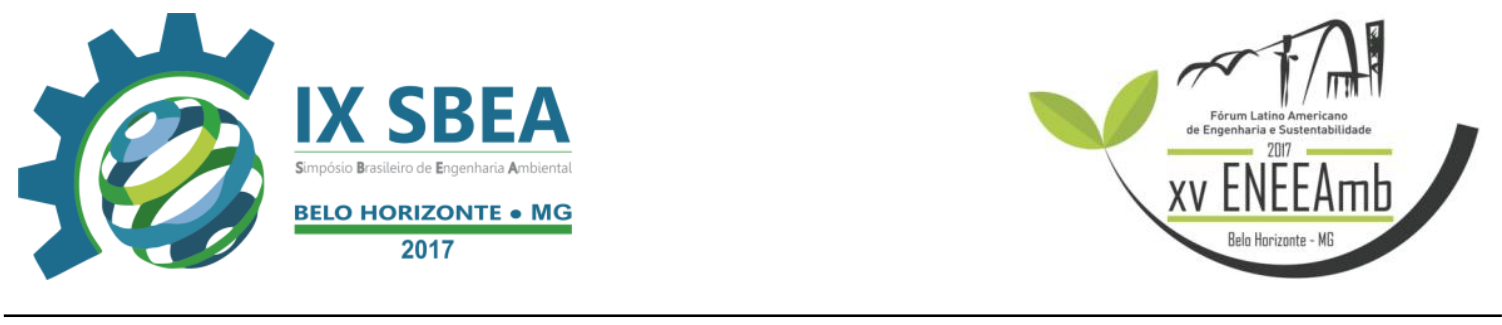

O estudo compreendeu o período 2012 e 2016, onde o levantamento das informações sobre os focos de calor foram realizados através do Instituto Nacional de Pesquisas Espaciais (INPE) que realiza o monitoramento utilizando imagens de satélites e disponibiliza estas informações em sua página na internet.

O processamento dos dados foi realizado através do software QGIS, onde a partir dos mapas em formato vetorial, disponibilizados pelo banco de dados do INPE, foi feita a seleção do município de interesse por meio de uma imagem vetorial, escala 1:100.000, extraídas do banco de dados do IBGE. Após a compilação dos dados vetoriais adquiridos, os mesmos foram sobrepostos à área de estudo, para iniciar o processo de interpretação das informações e geração de dados derivados. Foi feita a categorização da incidência dos focos de calor registrados por todos os satélites que possuem sensores óticos operando na faixa termal-média de 4um e que o INPE consegue receber, gerando os mapas subsequentes para anos em análise. O processamento da densidade dos focos ocorreu por meio do estimador de Kernel que desenha uma vizinhança circular ao redor de cada ponto da amostra, correspondendo ao raio de influência, e então aplica uma função matemática de 1 a 0 na posição do ponto, na fronteira da vizinhança (SOUZA et al., 2013). Para isso, utilizou-se cinco níveis de classificação dos focos: muito baixa, baixa, média, alta e muito alta, com raio 2000 e pixel de $100 \mathrm{~m}$.

\section{RESULTADOS E DISCUSSÃO}

O monitoramento dos focos de calor no munícipio de Salinas permitiu a visualização da dispersão desses fatores nas regiões do município, além da percepção e comprovação de uma relativa diminuição dos registros com o passar dos anos.

No ano de 2012 (Figura 3), há uma acentuada incidência na região nordeste da cidade, com focos mais dispersos e menos salientados. Pode-se presumir que a relevância demonstrada nessa região do município se deve ao alto índice de vegetação e presença em proximidade a comunidades rurais que realizam queimadas de forma não controlada. 

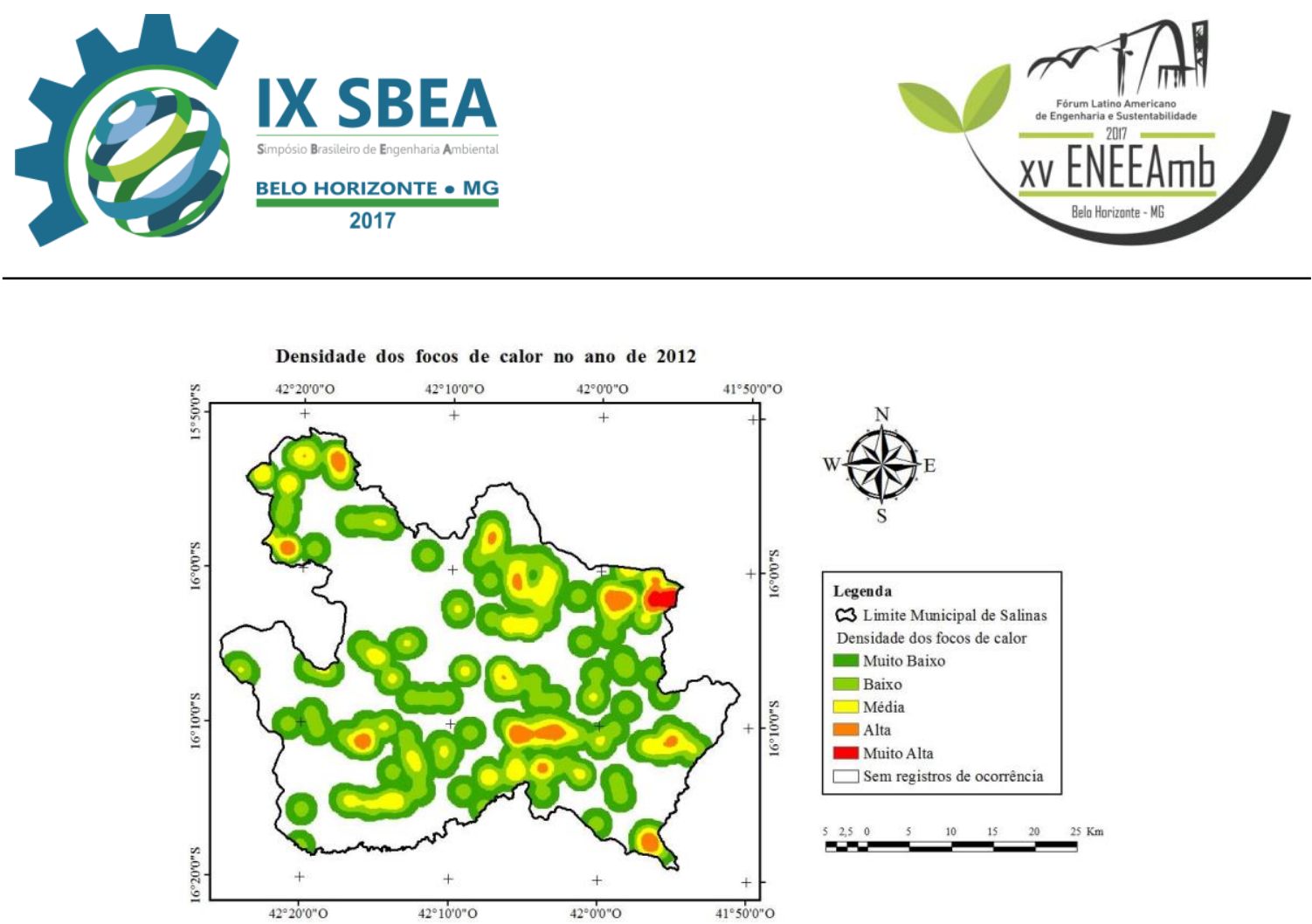

Figura 3 - Detecção de focos de calor no munícipio de Salinas, Minas Gerais durante o no ano de 2012.

No ano de 2013 verificou-se uma mudança drástica na distribuição espacial dos focos mais significativos (Figura 4), região caracterizada por solo exposto e cobertura vegetal desmatada, onde não há aceiros entre os terrenos. Essa relação é explicada pelo acúmulo de biomassa disponível nas áreas dessa região, que se torna material combustível disponível nos períodos sem registros de precipitação, em contrapartida com o aumento da fiscalização nas propriedades rurais na realização de queimadas, resultando na variação dos registros de calor relacionados a presença de fogo.

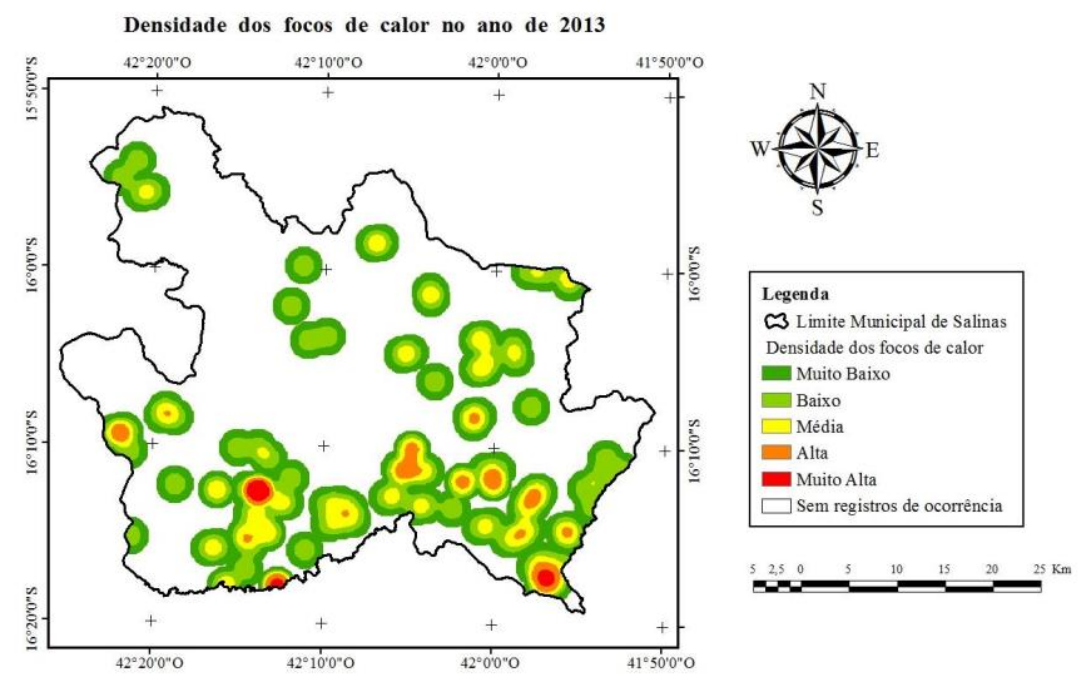

Figura 4 - Detecção de focos de calor no munícipio de Salinas, Minas Gerais durante o no ano de 2013. 


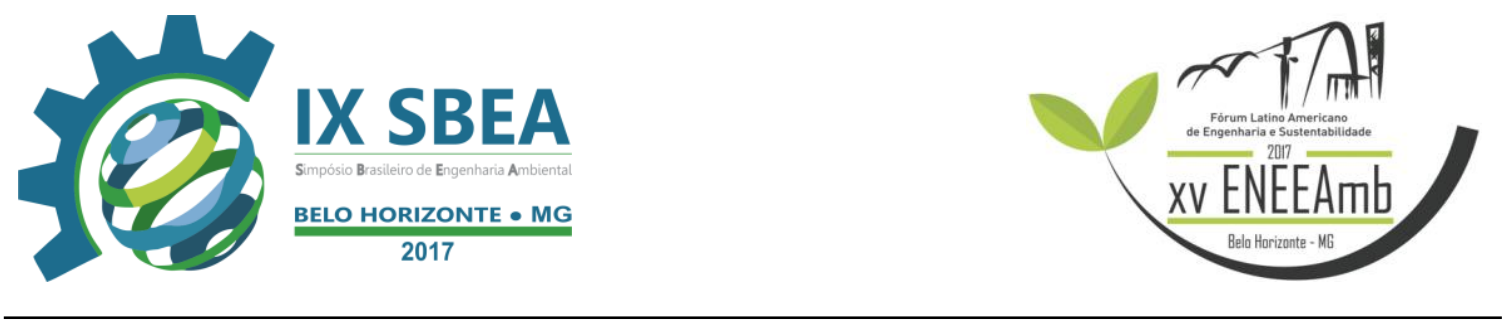

Já em 2014, houve uma dispersão em direções distintas do município (Figura 5), ano em que foram registradas temperaturas elevadas durante o ano e umidade relativa baixa (INMET, 2017), além do aumento de atividades agropecuárias e exploração desordenada que tem sido responsável pela ocorrência de incêndios nos últimos anos.

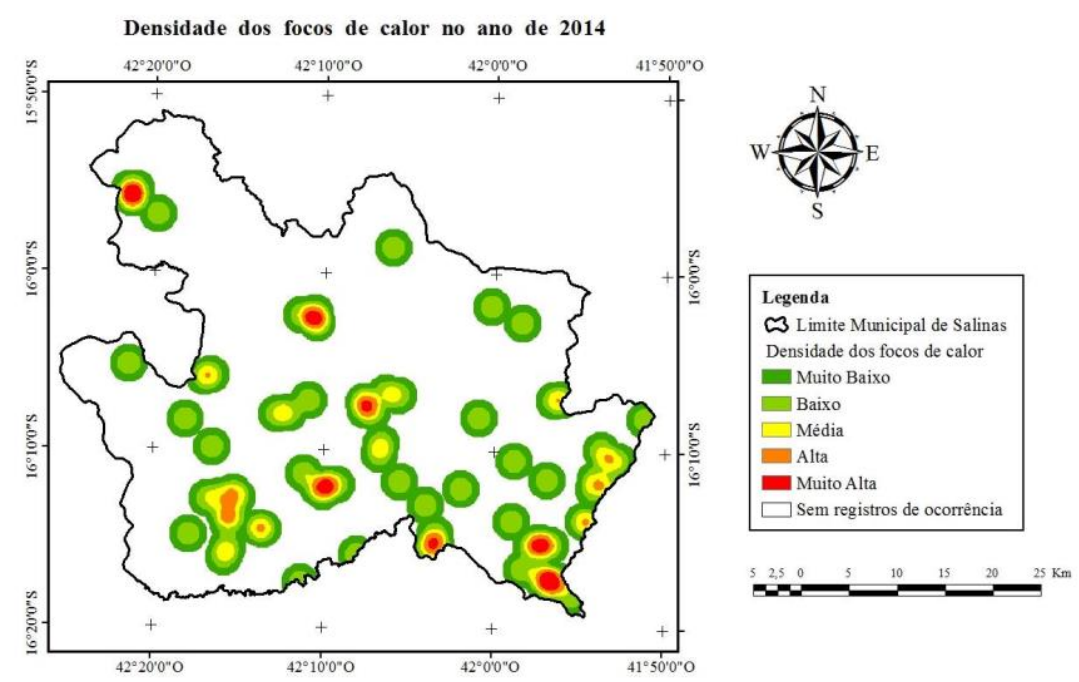

Figura 5 - Detecção de focos de calor no munícipio de Salinas, Minas Gerais durante o no ano de 2014.

Em 2015 e 2016 (Figura 6 e 7), mudanças na quantidade e nos focos de calor foram positivas, uma vez que modificaram sua dimensão, área de abrangência, podendo-se afirmar que houve menores registros corroborando com os registros do Instituto Estadual de Florestas para o município (IEF, 2017). Isso se deve as técnicas empregadas por alguns proprietários e ações do órgão, demonstrando que um dos principais fatores que influenciam na ocorrência dos incêndios são provenientes pelas atividades humanas decorrentes da tradição de usar o fogo como ferramenta de manejo agropecuário para criar pastagens, áreas para agricultura e facilitar a colheita. 

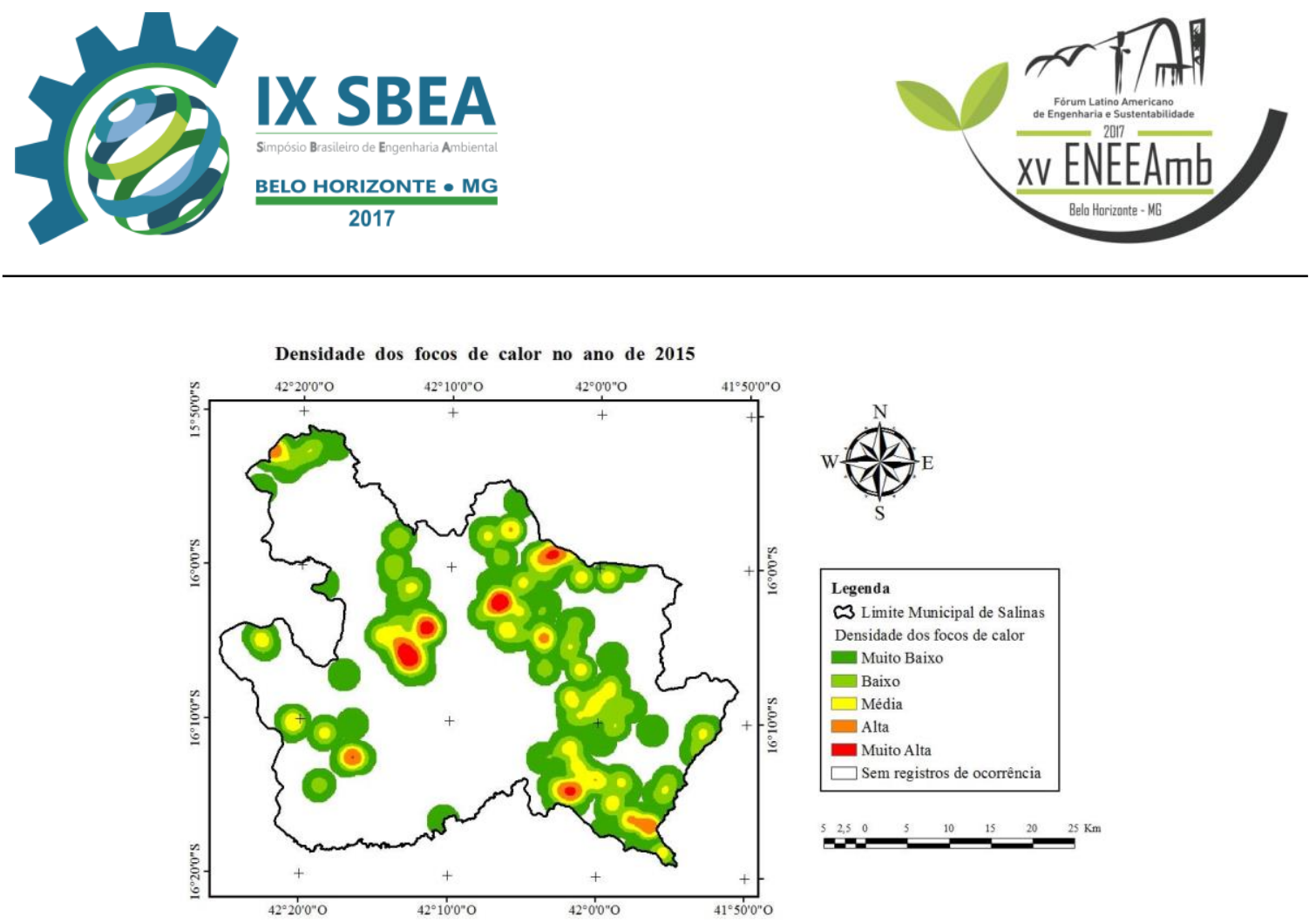

Figura 6 - Detecção de focos de calor no munícipio de Salinas, Minas Gerais durante o no ano de 2015.

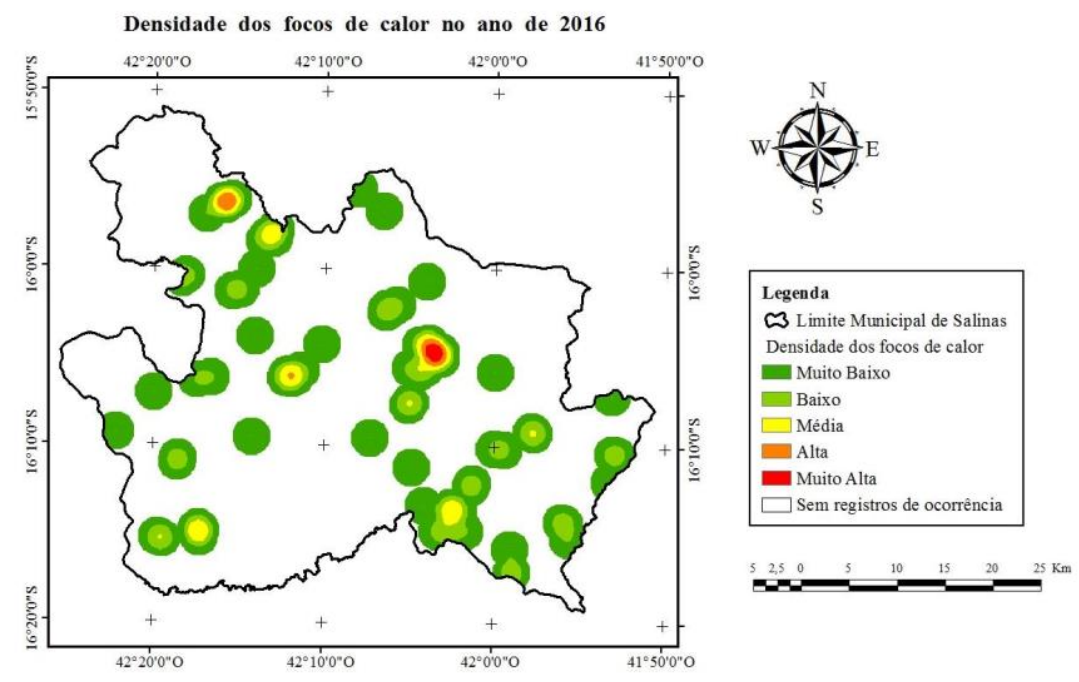

Figura 7 - Detecção de focos de calor no munícipio de Salinas, Minas Gerais durante o no ano de 2016.

\section{CONCLUSÕES/RECOMENDAÇÕES}

Com base nas análises dos resultados obtidos no município de Salinas - MG, as maiores ocorrências de focos de calor encontram-se próximas as rodovias, ou áreas do município que apresentam a pecuária como a principal atividade econômica, sendo fortemente determinadas pela ação humana. Observou-se índices muito altos de focos de calor nos períodos secos, o que pode estar relacionado às pressões antrópicas. A 


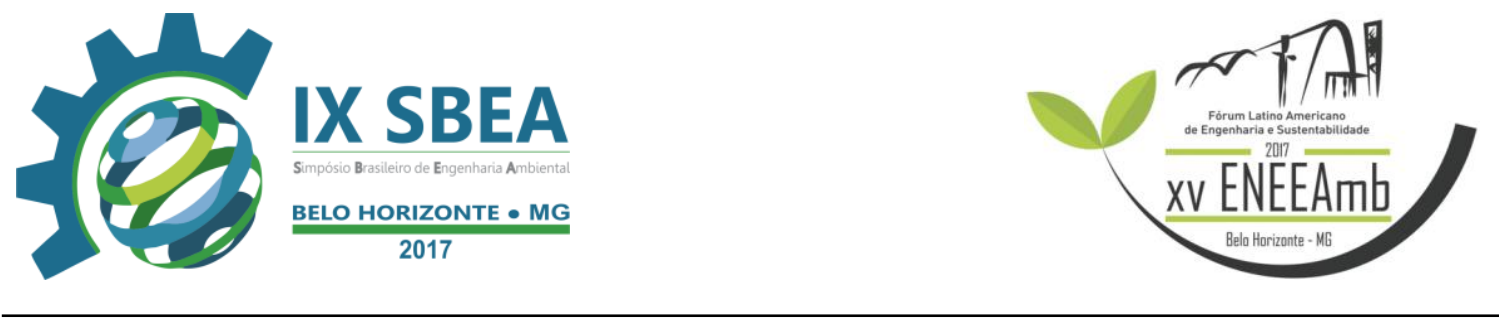

estimativa realizada pela função de Kernel apresentou a capacidade de predizer sobre a distribuição e intensidade dos focos permitindo conclusões sobre a espacialidade das áreas susceptibilidade, representando uma ferramenta com grande aplicabilidade no monitoramento e intepretação das causas dos incêndios no município mineiro.

\section{REFERÊNCIAS BIBLIOGRÁFICAS}

CIPRIANI, H. N.; PEREIRA, J. A. A.; SILVA, R. A.; FREITAS, S. G.; OLIVEIRA, L. T. Fire risk map for the Serra de São Domingos Park, Poços de Caldas, MG. Revista Cerne, Lavras, v. 17, n. 1, p. 77-83, 2011.

CORRÊA, C. R. Focos de queimadas em unidades de conservação. In: XVI Simpósio Brasileiro de Sensoriamento Remoto - SBSR, Foz do Iguaçu, Paraná. Anais... Paraná: INPE, 2013. p. 3-6 Disponível em: http://www.dsr.inpe.br/sbsr2013/files/p0968.pdf. Acesso em: 23 de maio de 2017.

FIEDLER, N. C.; MERLO, D. A.; MEDEIROS, M. B. Ocorrência de incêndios florestais no Parque Nacional da Capada dos Veadeiros, Goiás. Revista Ciência Florestal, Santa Maria, v. 16, n. 2, p. 153-161, 2006.

IBGE. Instituto Brasileiro de Geografia e Estatística. Censo Demográfico: estimativa da população 2016. Disponível em: http://cidades.ibge.gov.br/xtras/perfil.php?codmun=315700. Acesso em: 30 de Abril de 2017.

IEF. Instituto Estadual de Florestas. Banco de notícias 2017: ocorrência de incêndios nos municípios mineiros. Disponível em: <http://www.ief.mg.gov.br/noticias/1/782focos-de-calor-e-area-queimada-por-incendios-florestais-diminuem-em-minas-gerais $>$. Acesso em: 17 de Maio de 2017.

INMET. Instituto Nacional de Meteorologia. Rede de Estações Automáticas 2017. Disponível em: http://www.inmet.gov.br/portal/index.php?r=home/page\&page=rede_estacoes_auto_gra f. Acesso em: 20 de maio de 2017.

INPE - Instituto Nacional de Pesquisas Espaciais, 2012. Portal do Monitoramento de Queimadas e Incêndios. Disponível em http://queimadas.cptec.inpe.br. Acesso em: 12 de maio de 2017.

INPE. Instituto Nacional de Pesquisas Espaciais, 2016. Portal do Monitoramento de Queimadas e Incêndios. Disponível em: http://www.inpe.br/queimadas. Acesso em: 20 abr. 2017. 


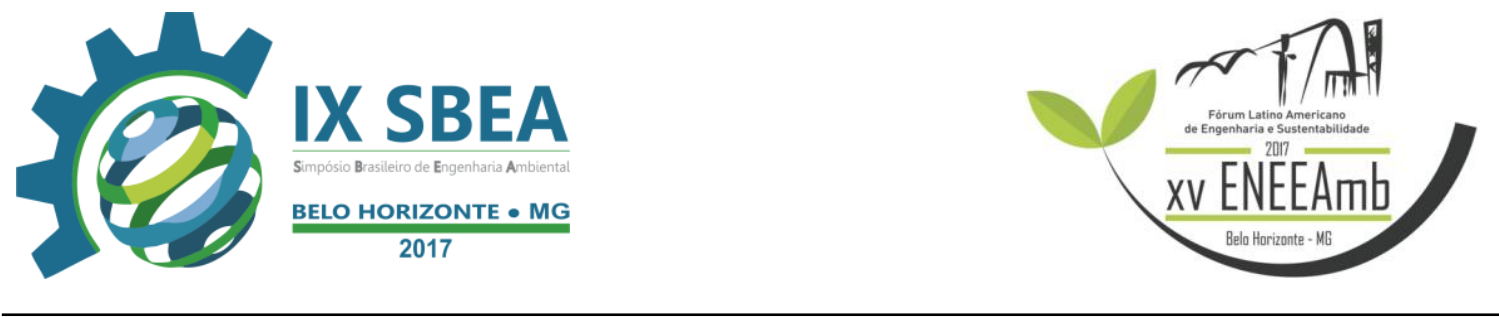

MIRANDA, J. R.; SILVA, R. G.; SALES, G. B. FILGUEIRAS, R.; NASCIMENTO, C.R. Caracterização e monitoramento de focos de queimadas na região norte de Minas Gerais a partir de imagens de satélites. In: XVI Simpósio Brasileiro de Sensoriamento Remoto - SBSR, Foz do Iguaçu, Paraná. Anais... Paraná: INPE, 2013. p.3-4

SOUZA, N. P.de; SILVA, E. M. G. C; TEIXEIRA, M. D; LEITE, L. R; REIS, A. A. dos ; SOUZA, L. N. de ; JUNIOR, F. W. A; RESENDE, T. A. Aplicação do estimador de densidade Kernel em Unidades de Conservação na bacia do Rio São Francisco para análise de focos de desmatamento e focos de calor. In: Anais XVI Simpósio Brasileiro de Sensoriamento Remoto - SBSR, Foz do Iguaçu, PR. 2013. 